\title{
Novel anterior cruciate ligament graft fixation device reduces slippage
}

This article was published in the following Dove Press journal:

Medical Devices: Evidence and Research

13 May 2013

Number of times this article has been viewed

\author{
Mandi J Lopez' \\ Allen Borne ${ }^{2}$ \\ W Todd Monroe ${ }^{3}$ \\ Prakash Bommala' \\ Laura Kelly' \\ Nan Zhang' \\ 'Laboratory for Equine and \\ Comparative Orthopedic Research, \\ Department of Veterinary Clinical \\ Sciences, School of Veterinary \\ Medicine, Louisiana State University, \\ Baton Rouge, ${ }^{2}$ Louisiana State \\ University, New Orleans Health \\ Sciences Center, School of Medicine, \\ New Orleans, ${ }^{3}$ Department \\ of Biological and Agricultural \\ Engineering, Agricultural Center, \\ Louisiana State University, Baton \\ Rouge, LA, USA
}

Correspondence: Mandi J Lopez Veterinary Clinical Sciences Department, School of Veterinary Medicine, Louisiana State University and Agricultural and Mechanical College, Skip Bertman Drive, Baton Rouge, LA 70803, USA Email mlopez@lsu.edu
Abstract: Clinically significant laxity occurs in 10\%-30\% of knees after anterior cruciate ligament reconstruction. Graft slippage and tension loss at the hamstring graft tibial fixation site during and after reconstruction surgery contribute to postoperative joint laxity and are detrimental to long-term knee stability and graft properties. Limiting graft slippage will reduce associated complications. We sought to compare the in vitro mechanical properties and in vivo joint stabilization, postoperative limb use, and graft incorporation of the novel GraftGrab ${ }^{\mathrm{TM}}$ (GG) device designed to reduce hamstring graft tibial fixation slippage with the commercially available bioabsorbable Bio-Post ${ }^{\mathrm{TM}}$ and spiked washer (BP). Mechanical testing was performed on canine tibia-hamstring graft constructs to quantify initial fixation properties. In vivo joint stabilization, postoperative limb use and graft incorporation of hamstring graft reconstructions were determined in a canine model. Outcomes included tibial translation and ground reaction forces preoperatively and 4 and 8 weeks postoperatively, three-dimensional graft and bone tunnel dimensions at the latter two time points, and graft-bone microstructure, as well as mechanical properties 8 weeks after implantation. Immediately after fixation, all grafts slipped from the BP constructs versus about $30 \%$ of GG constructs. In vivo limb use remained low, and tibial translation increased with time in the BP cohort. These results together confirm that initial graft slippage is lower with GG versus BP extracortical hamstring graft tibial fixation. In addition, postoperative recovery and joint stability are more consistent with the GG. This information supports the GG as an alternative to extracortical tibial hamstring graft fixation that has procedural advantages over current implants and reduces graft failure from slippage.

Keywords: cruciate, implant, bioabsorbable, canine, graft, tibia

\section{Introduction}

Soft tissue anterior cruciate ligament (ACL) graft reconstruction with hamstring tendon grafts is a common procedure. ${ }^{1-6} \mathrm{Up}$ to $17 \%$ of patients suffer from ACL reconstruction laxity failure attributable to graft tension loss during implantation and postoperative cyclical loading. ${ }^{5,7-9}$ To avoid recurrent joint instability, an increase in joint laxity should be avoided, ${ }^{10}$ but clinically significant knee laxity occurs in $10 \%-30 \%$ of knees within 4 months of ACL reconstruction. ${ }^{11,12}$

The ability to estimate and maintain graft length and tension is compromised by implants that require multiple maneuvers during application. ${ }^{9,13,14}$ Postoperative slippage at the fixation sites, graft elongation, and reduced graft construct stiffness contribute to increases in joint laxity. ${ }^{15}$ The tibial fixation is the weakest point of a femur-graft-tibia construct after hamstring graft ACL reconstruction, and graft lengthening at the tibial fixation is often due to failure at the graft-fixation device interface. ${ }^{11,16,17}$ Cortical and 
intratunnel hamstring graft fixation are largely comparable. ${ }^{18-21}$ With contemporary cortical and tunnel implants, graft tension decreases and knee laxity increases following in vitro device application and loading of tibial hamstring graft fixations. ${ }^{9}$ In addition, the strong initial tibial fixation required for postoperative rehabilitation is difficult to achieve and maintain until graft incorporation using conventional devices. . $^{5,22}$ Devices to optimize soft tissue graft fixation to the tibia are needed to reduce graft slippage and joint laxity.

The GraftGrab ${ }^{\text {TM }}$ (GG, Tesa Medical, Inc., Worcester, MA, USA) was designed to reduce joint laxity associated with graft slippage and to obviate the need for specialized instrumentation and site preparation for graft fixation. The purpose of this study was to compare this novel, bioabsorbable device with the commercially available bioabsorbable screw and washer (Bio-Post ${ }^{\mathrm{TM}}$ and spiked washer [BP, Arthrex, Naples, FL, USA]) in a canine hamstring graft cranial cruciate ligament (analogous to human ACL) reconstruction model. The in vitro mechanical properties as well as in vivo joint laxity, graft and bone tunnel dimensions, postoperative limb use, and graft microstructure were evaluated. We hypothesized that in vitro graft slippage would be lower and postoperative joint stability higher with the GG than with the BP.

\section{Materials and methods}

This investigation was initiated after approval by the Institutional Animal Care and Use Committee (Protocol 10-004).

\section{Study design}

Hamstring grafts were fixed to the medial tibial cortical surface with a BP and spiked washer or with a GG in paired adult canine cadaver limbs ( $\mathrm{n}=6$ per cohort). Tibia-graft constructs were tested to failure in tension (in vitro study). Next, hamstring graft reconstructions were performed in one stifle (canine knee) of 14 dogs $(4.1 \pm 0.3$ years, $23 \pm 2.4 \mathrm{~kg}$, mean \pm standard deviation) (in vivo study). ${ }^{23,24}$ Grafts were secured to the femur with an Endobutton ${ }^{\text {TM }}$ CL Ultra (Smith and Nephew, Andover, MA, USA) and to the tibia with a BP or a $\mathrm{GG}(\mathrm{n}=7$ per cohort $) .{ }^{25}$ Joint laxity ${ }^{26}$ and ground reaction forces $^{27}$ were quantified before and at 4 and 8 weeks after surgery, and computed tomography scans were performed at the latter time points. After sacrifice 8 weeks after surgery (Beuthanasia-D Special ${ }^{\circledR}$, Schering-Plough Animal Health, Union, NJ, USA), mechanical testing was performed on tibia-graft constructs, ${ }^{25}$ and graft integration into tibial bone tunnels was evaluated with light microscopy. ${ }^{23}$

Power analysis revealed that to detect a mean difference in failure strength of $27.9 \mathrm{~N}$, ie, a $30 \%$ difference, the sample size needed to obtain a power of at least $0.75(\alpha=0.05)$ was six samples using the Student's $t$-test (effect size 0.9). ${ }^{25}$ A difference of $27.9 \mathrm{~N}$ is approximately $16.5 \%$ of the walking force, ie, $169 \mathrm{~N}$, experienced by the human ACL during level walking. ${ }^{12}$ The same sample size was needed to detect a minimum difference of 1.5 (unitless) normalized total tibial translation (joint laxity) at power of 0.8 using multivariate analysis of variance (effect size 0.9 ). ${ }^{26} \mathrm{We}$ had 12 joints available for the initial mechanical testing study and 14 canines available for the in vivo study; thus, there were 12 grafts $(n=6$ per treatment) available for the initial mechanical testing, and 14 joints ( $\mathrm{n}=7$ per treatment) available for in vivo and post mortem assessments.

\section{Implants}

The GG (Figure 1A) has two parts, a base (diameter, $19.0 \mathrm{~mm}$; height, $5.5 \mathrm{~mm}$ ) and an interconnecting cap composed of poly-L-lactic acid, a bioabsorbable polymer. ${ }^{28}$ The base has a central hole with an attached hollow sleeve ( $3 \mathrm{~mm}$ long, $5.5 \mathrm{~mm}$ outer diameter, $4.5 \mathrm{~mm}$ inner diameter) extending from the flat surface of the base into the bone tunnel. On the opposite surface are struts with notches for the cap hinge on one side and serrations that interdigitate with cap serrations on the opposite side. The hinge of the cap is snapped onto the struts and the graft is pulled through the hollow sleeve as it is pressed into the bone tunnel such that the flat surface of the washer abuts bone. The graft is tensioned, positioned across the base $90^{\circ}$ to the bone tunnel, and then secured by pressing the free end of the cap onto the base. The tapered BP (10 mm head, $6.35 \mathrm{~mm}$ maximum cancellous thread diameter) and spiked washer (10 spikes, height $4.5 \mathrm{~mm}$, Figure 1B) are also composed of poly-L-lactic acid.

\section{Graft preparation}

Grafts harvested from the gracilis, semitendinosus, and cranial tibialis fascia were trimmed to a width and length of $1 \mathrm{~cm} \times 15 \mathrm{~cm}$, twisted to a diameter of $4.5 \mathrm{~mm}$, and wrapped in a Chinese finger trap of \#2 polyglactin $910 .{ }^{23}$ For in vitro GG fixations, the graft was passed through a $4.5 \mathrm{~mm}$ tibial tunnel from the cranial aspect of the gracilis-semitendinosus insertion to the articular insertion of the cranial cruciate liga-
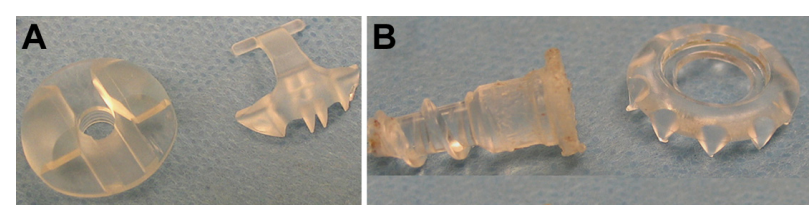

Figure I GraftGrab (A) and Bio-Post (B). 
ment, leaving $2 \mathrm{~cm}$ exiting the tunnel distally and $6 \mathrm{~cm}$ at the joint surface. Tension was applied to the proximal graft while the distal aspect was pulled taut and secured. For BP fixations, a $3.2 \mathrm{~mm}$ tunnel $7 \mathrm{~mm}$ distal to the graft tunnel and perpendicular to the tibial long axis was decorticated to a diameter of $6.5 \mathrm{~mm}$ and tapped. A BP was passed through a washer and engaged in bone, and the graft was passed around the BP, tensioned as above, and secured by advancing the screw and washer.

\section{Mechanical testing}

Rear limbs harvested immediately post mortem were stored at $-20^{\circ} \mathrm{C}$ and thawed on the day of testing or tested within 2 hours of harvest 8 weeks after graft reconstruction. Tibiae were potted with polyester resin in aluminum cylinders for mechanical testing after removal of all soft tissues. A $12 \mathrm{~mm}$ diameter cross pin through the cylinder and bone $40 \mathrm{~mm}$ from the cylinder's proximal edge was used to affix the specimen to a custom testing fixture attached to the load cell of a materials testing system (8841 Dynamite, Instron ${ }^{\circledR}$, Canton, MA, USA). Within the fixture, the specimen had $2^{\circ}$ of freedom in the horizontal plane. The fixture itself had unconstrained rotation about an axis perpendicular to the cross pin (Figure 2). The graft was clamped in pneumatic versa grips with serrated faces (Instron ${ }^{\circledR}$ ) $5 \mathrm{~mm}$ from the articular surface and a $5 \mathrm{~N}$ preload applied so that the graft and bone tunnel became aligned with the direction of tension. The testing fixture was then immobilized for testing. A single cycle load to failure (60 $\mathrm{mm}$ per minute) was applied following three conditioning cycles ( $2 \%$ strain, $0.5 \mathrm{~Hz}$ ). Stiffness, yield and failure load, displacement, and energy were derived from load displacement curves $(60 \mathrm{~Hz}$ sampling rate).

\section{Surgical graft reconstruction}

The animal model was consistent with a single bundle ACL reconstruction stabilized proximally with an Endobutton and extracortical fixation distally. ${ }^{2}$ Dogs were anesthetized and the surgical sites aseptically prepared. After graft harvest and preparation ${ }^{23}$, the native cranial cruciate ligament was excised sharply through a medial arthrotomy, and the tibial bone tunnel created. A $4.5 \mathrm{~mm}$ bone tunnel was created from the femoral cranial cruciate ligament origin exiting $7 \mathrm{~mm}$ lateral to the proximal third of the lateral trochlear ridge. The graft was passed abaxially through the femoral tunnel with about $1 \mathrm{~cm}$ extending beyond the cortical surface, and a transfixation suture (\#2 Ethibond Excel ${ }^{\mathrm{TM}}$, Ethicon Inc, Somerville, NJ, USA) was placed $7 \mathrm{~mm}$ from its end. The

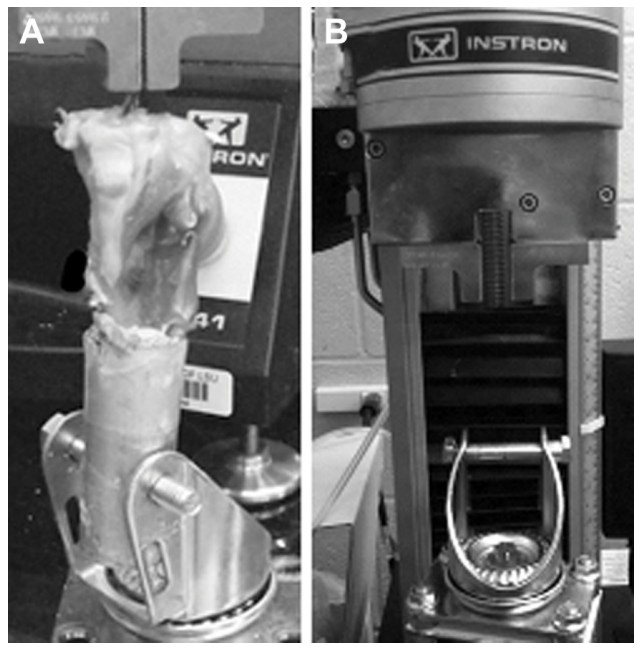

Figure 2 Testing fixture with (left) and without (right) tibial specimen.

Endobutton suture loop was removed and the polyglactin 910 suture tags on the graft were passed through the middle two holes while the polyester suture tags were passed through the two outer holes, and both were tied. Tension was applied to the articular end of the graft to seat the Endobutton and remove graft laxity prior to passing it abaxially through the tibial tunnel. Tension was applied with the joint in about $135^{\circ}$ of flexion (standing angle) until drawer motion was negligible, and the graft was secured with either a GG or BP as described above.

\section{Joint laxity}

Anterior-posterior tibial translation was quantified using an established device (DGY 2000 ${ }^{\mathrm{TM}}$ ) with the dogs under general anesthesia and the joint in $135^{\circ}$ of flexion. ${ }^{26}$ All radiographic exposures included the whole tibia and the distal third of the femur (Sound Technologies, Carlsbad, CA, USA). Joint positioning on the device was confirmed on a radiograph performed with no force applied, ie, a zero force radiograph. Subsequently, force $(66.7 \mathrm{~N}, 15 \mathrm{lb})$ was applied to the anterior tibia with the femur held in place, and an exposure was made, ie, an anterior force radiograph. Force was applied to the posterior tibia for the posterior force radiograph. Total tibial, posterior tibial, and anterior tibial translation were measured on superimposed anterior and posterior force radiographs, anterior and zero force radiographs, and posterior and zero force radiographs, respectively. For measurements, tibiae were aligned and the distance between the most posterior point of the femoral condyle determined (Adobe Photoshop CS version 8.0, Adobe Systems Inc, Seattle, WA, USA). Translation was normalized to tibial width by dividing translation by tibial width and multiplying by $100 .^{26}$ 

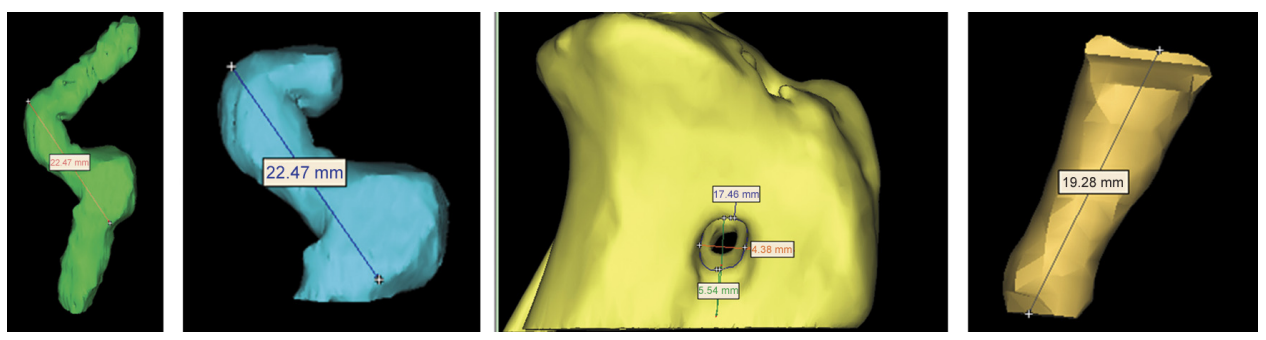

Figure 3 Three-dimensional reconstructions (from left to right) of graft (anteroposterior), intra-articular graft (anteroposterior), cortical surface of tibial tunnel (mediolateral), and tibial tunnel (anteroposterior)

\section{Three-dimensional computed tomography}

Computed tomography (LightSpeed VCT \#2335179-2, Medical Systems, Milwaukee, WI, USA) scans were performed during the same general anesthesia as radiographs (KV 120, MA 440, $0.625 \mathrm{~mm}$ slice width) with the stifles in full extension ( $30^{\circ}$ flexion). Three dimensional reconstructions of knee joints were generated from two-dimensional computed tomographic slices (Mimics, version 11.1, Materialise, Leuven, Belgium). Reconstruction threshold limits were set at 537-3056 Hounsfield units. Intra-articular graft length, surface area and volume, total graft surface area and volume, and tibial bone tunnel volume and cortical aperture diameter were quantified (Figure 3). ${ }^{29}$

\section{Gait analysis}

Kinetic gait analysis was performed preoperatively and 4 and 8 weeks after surgery (Force platform model \# OR6-WP-1000, Advanced Medical Technology Inc, Newton, MA, USA). ${ }^{30}$ Data logging (100 Hz, Acquire version 7.3, Sharon Software Inc, Dewitt, MI, USA) was triggered by a force of $5 \mathrm{~N}$ on the force platform. Five successful trials at a velocity of $1.0-2.0 \mathrm{~m} / \mathrm{sec}$ and acceleration of 0.9 to $-0.9 \mathrm{~m} / \mathrm{sec}^{2}$ were recorded for each limb at each time point. Mean vertical impulse and peak vertical force normalized to body weight, were used for statistical analyses.

\section{Light microscopy (histology)}

After mechanical testing described above, specimens were fixed in $10 \%$ neutral buffered formalin, and the proximal one third of each fixed tibia was sectioned sagittally. Tissues were embedded in paraffin, and sections $(5 \mu \mathrm{m})$ were stained with Masson's Trichrome and hematoxylin and eosin. Graft integration and maturation were evaluated with light microscopy.

\section{Statistical analysis}

All results are reported as the mean \pm standard deviation. Mechanical testing values were compared with paired (in vitro) and unpaired (in vivo) Student's $t$-tests (GraphPad Prism, Version 4.0, GraphPad Software Inc, La Jolla, CA, USA). A multivariate analysis of variance was used to evaluate the fixed effects of treatment (unoperated, $\mathrm{BP}, \mathrm{GG}$ ) on in vivo collinear response variables (SAS version 8.0; SAS Institute, Cary, NC, USA). All variables were considered continuous and tested for normality using the Shapiro-Wilk statistic. The random variance of dogs nested within treatment was used as the treatment effect error term. For responses measured over time, a repeated-measures

Table I Tensile properties (mean \pm standard deviation) of tibial anterior cruciate ligament fixation with a GraftGrab ${ }^{\mathrm{TM}}$ or Bio-Post ${ }^{\mathrm{TM}}$ and spiked washer immediately after fixation and 8 weeks after implantation

\begin{tabular}{|c|c|c|c|c|c|c|}
\hline & \multicolumn{3}{|c|}{ Immediately post-fixation (in vitro) } & \multicolumn{3}{|c|}{8 weeks after implantation (in vivo) } \\
\hline & $\begin{array}{l}\text { GraftGrab } \\
n=6\end{array}$ & $\begin{array}{l}\text { Bio-Post } \\
\mathrm{n}=6\end{array}$ & $P$ & $\begin{array}{l}\text { GraftGrab } \\
n=7\end{array}$ & $\begin{array}{l}\text { Bio-Post } \\
n=7\end{array}$ & $P$ \\
\hline Failure load $(\mathrm{N})$ & $246.5 \pm 29.7$ & $208.9 \pm 66.1$ & 0.30 & $|4| .4 \pm 34.02$ & $116.9 \pm 57.7$ & 0.35 \\
\hline Failure elongation $(\mathrm{mm})$ & $20.4 \pm 3.7$ & $17.1 \pm 5.2$ & 0.35 & $6.7 \pm 2.3$ & $6.7 \pm 2.2$ & 0.98 \\
\hline Yield load $(\mathrm{N})$ & $201.9 \pm 46.2$ & $151.3 \pm 57.9$ & 0.24 & $115.1 \pm 41.0$ & $103.9 \pm 46.3$ & 0.64 \\
\hline Yield elongation (mm) & $13.9 \pm 4.2$ & $10.3 \pm 3.5$ & 0.27 & $4.8 \pm 1.2$ & $4.8 \pm 1.9$ & 0.95 \\
\hline Stiffness $(\mathrm{N} / \mathrm{mm})$ & $20.3 \pm 7.9$ & $15.4 \pm 3.6$ & 0.22 & $30.5 \pm 11.1$ & $24.2 \pm 5.6$ & 0.21 \\
\hline Yield strain energy $(\mathrm{J})$ & $1.6 \pm 0.7$ & $\mathrm{I} . \mathrm{I} \pm 0.7$ & 0.34 & $0.3 \pm 0.1$ & $0.4 \pm 0.3$ & 0.67 \\
\hline Failure strain energy $(\mathrm{J})$ & $3.4 \pm 1.1$ & $2.5 \pm 1.2$ & 0.33 & $0.5 \pm 0.2$ & $0.6 \pm 0.4$ & 0.66 \\
\hline Tunnel length (mm) & $26.2 \pm 1.1$ & $27.0 \pm 2.08$ & 0.29 & $21.8 \pm 2.7$ & $21.8 \pm 4.8$ & 1.0 \\
\hline
\end{tabular}


multivariate analysis of variance was performed following addition of the fixed effect of time. Wilks' $\lambda$ was evaluated first for interaction effects and then for main effects. If there were significant interactions of treatment and/or time for significant univariate analyses, comparisons within or between treatments were performed using Tukey's adjustment to maintain type I error at 0.05 .

\section{Results}

\section{Mechanical testing}

Outcome measures applied in this study are established and validated, with the exception of the three-dimensional volumes which were performed as reported in previous publications by the investigators..$^{23,25-27,30,31}$ All limbs were used for mechanical testing, 12 limbs from the in vitro study ( $\mathrm{n}=6$ per fixation, GG or BP) and 14 limbs from the in vivo study ( $\mathrm{n}=7$ per fixation, $\mathrm{GG}$ or BP). Immediately after fixation (in vitro study), two grafts failed at the GG implant, two slipped from the fixation, and two failed mid substance, while all grafts slipped from the BP washer. Eight weeks after implantation (in vivo study), three GG constructs failed at the articular surface and four in the graft mid substance while four BP constructs failed at the articular surface and three in the graft mid substance.
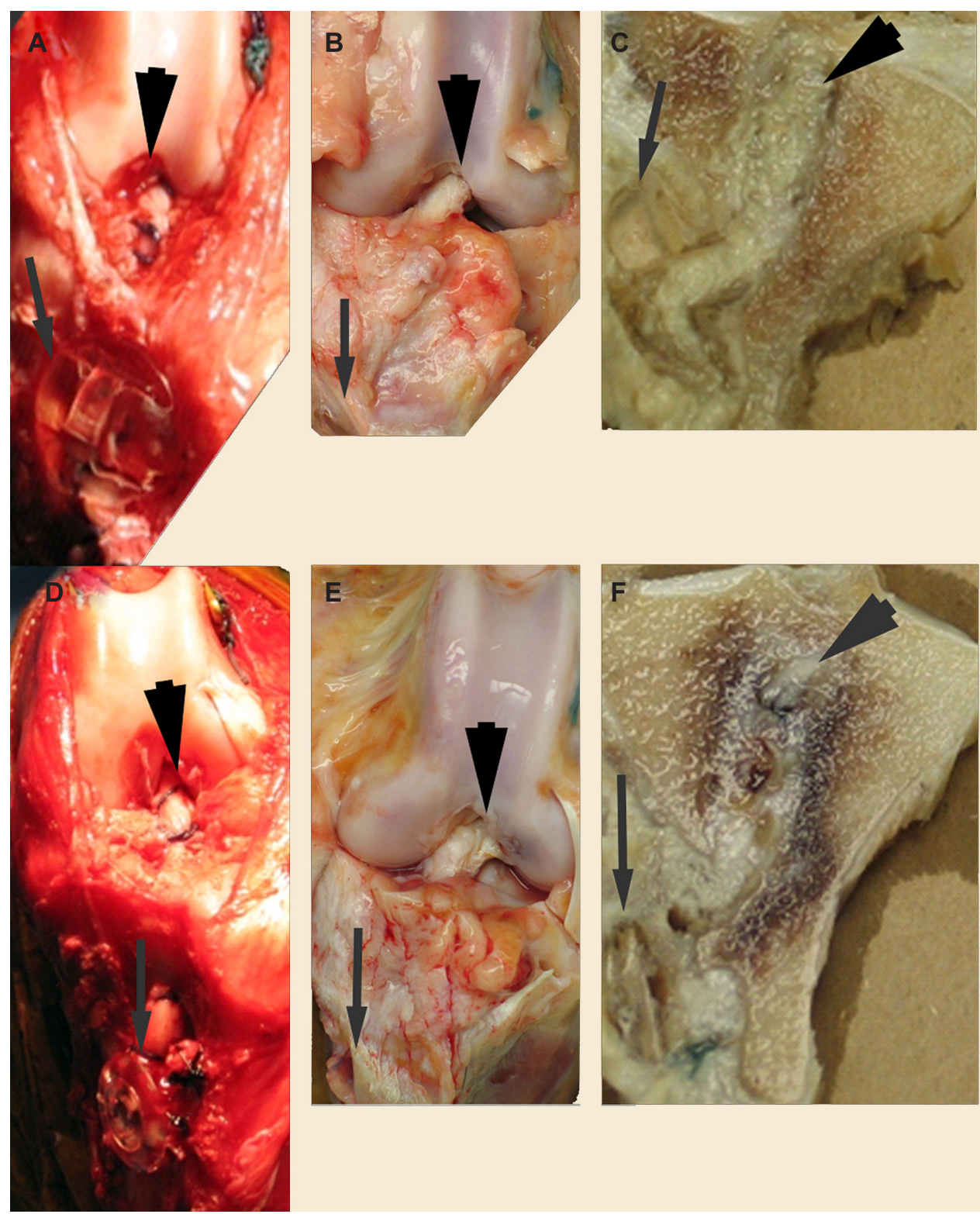

Figure $4 \mathrm{GraftGrab}^{\mathrm{TM}}$ (upper) and BioPost ${ }^{\mathrm{TM}}$ (lower) graft reconstructions during surgery (A and $\left.\mathbf{D}\right), 8$ weeks after implantation (B and $\left.\mathbf{E}\right)$ and after sagittal sectioning (C and F).

Note: Grafts are indicated by large black arrows and implants by small, gray arrows. 
Mechanical measures were not significantly different between implants immediately after fixation (in vitro study) or 8 weeks after implantation (in vivo study, Table 1).

\section{Joint laxity}

Based on post mortem examination, all joints had minimal effusion and mild to moderate synovitis (Figure 4). Grafts were robust and intact in all dogs except one GG animal with a partial proximomedial graft defect (10\%). Posterior tibial translation was significantly greater 8 weeks after surgery compared with presurgical values in the BP group $(P=0.01)$. There were no differences in tibial translation between implant cohorts at any point (Table 2).

\section{Three-dimensional computed tomography}

Measures performed on three-dimensional computed tomography reconstructions showed that graft and bone tunnel dimensions were not different between the treatment groups at any time or within treatment groups over time (Table 3).

\section{Gait analysis}

The peak vertical force was significantly greater for unoperated limbs versus those containing implants 4 weeks $(P<0.001)$ and 8 weeks $(P<0.001)$ after surgery (Table 4$)$. It was significantly lower for limbs containing GG implants 4 weeks $(P<0.001)$ and 8 weeks $(P<0.001)$ after surgery compared with preoperative values, and values were significantly lower 4 weeks versus 8 weeks after surgery $(P<0.001)$. Results were identical in the BP cohort, with preoperative values in implanted limbs being lower than in nonoperated limbs at 4 weeks $(P<0.001)$ and 8 weeks $(P<0.001)$ after surgery, and 4-week implanted limb values were lower than 8 -week values $(P<0.05)$. The unoperated limb vertical impulse values were significantly greater than for operated limbs 4 weeks $(P<0.001)$ and 8 weeks $(P<0.001)$ after surgery (Table 4$)$.
The vertical impulse was significantly lower 4 weeks $(P<0.001)$ and 8 weeks $(P<0.001)$ after surgery compared with preoperative values in limbs containing GG, and values were significantly lower 4 weeks versus 8 weeks $(P<0.001)$ after surgery. There was no difference between the 4-week and 8-week vertical impulse in operated limbs within the BP cohort. The vertical impulse results were otherwise identical. Differences between GG and BP cohorts were not significant at any time point.

\section{Light microscopy (histology)}

All grafts were well integrated in bony tunnels 8 weeks after implantation. Graft microstructure in both cohorts was consistent with early ligamentization. ${ }^{32}$ There were regions of elongated fibroblasts between parallel collagen fibers interspersed with areas with plump fibroblasts encased in amorphous extracellular matrix among poorly aligned collagen fibers (Figure 5A). Graft attachment to bone included rare points of fibrous attachment (Figure 5B), and direct (Figure 5C) and indirect (Figure 5D) insertions. Direct insertions were more prominent at the proximal aspect of the bony tunnels and indirect insertions closest to the implants.

\section{Discussion}

Clinical reports indicate that a significant number of knees become unstable after ACL reconstruction, ${ }^{9,13,33}$ many due to graft slippage at the tibial fixation site. Tension loss from slippage can occur during surgical fixation, in the immediately postoperative period, and with cyclic loading. ${ }^{11,16,17}$ Graft slippage and joint laxity occurs with currently available devices, often resulting in use of hybrid (dual) tibial fixation devices. ${ }^{9,34}$ The GG, a novel, bioabsorbable, extracortical fixation device, is designed to reduce graft slippage during and after surgery to prevent postoperative joint laxity. The fewer maneuvers required for graft fixation and lack of need for custom instrumentation or site preparation are procedural advantages of the GG over many existing devices.

Table 2 Posterior, anterior, and total tibial translation (normalized to tibial width) in limbs containing GraftGrab ${ }^{\mathrm{TM}}$ or Bio-Post $^{\mathrm{TM}}$ implants preoperatively, 4 and 8 weeks after cranial cruciate ligament reconstruction (mean \pm standard deviation)

\begin{tabular}{|c|c|c|c|c|c|c|c|c|c|}
\hline & \multicolumn{3}{|c|}{ Posterior tibial translation } & \multicolumn{3}{|c|}{ Anterior tibial translation } & \multicolumn{3}{|c|}{ Total tibial translation } \\
\hline & $\begin{array}{l}\text { Before } \\
\text { surgery }\end{array}$ & Week 4 & Week 8 & $\begin{array}{l}\text { Before } \\
\text { surgery }\end{array}$ & Week 4 & Week 8 & $\begin{array}{l}\text { Before } \\
\text { surgery }\end{array}$ & Week 4 & Week 8 \\
\hline $\begin{array}{l}\text { GraftGrab } \\
n=7\end{array}$ & $6.3 \pm 1.4$ & $9.6 \pm 2.0$ & $10.2 \pm 4.2$ & $9.1 \pm 2.9$ & $16.5 \pm 10.8$ & $15.9 \pm 9.2$ & $14.4 \pm 4.3$ & $25.5 \pm 10.5$ & $26.2 \pm 9.3$ \\
\hline $\begin{array}{l}\text { Bio-Post } \\
n=7\end{array}$ & $5.9 \pm 1.9^{*}$ & $9.8 \pm 3.2^{* * * *}$ & $10.8 \pm 3.9 * *$ & $8.5 \pm 2.2$ & $9.9 \pm 2.9$ & $12.2 \pm 5.6$ & $14.5 \pm 3.7$ & $19.2 \pm 6.2$ & $21.7 \pm 7.7$ \\
\hline
\end{tabular}

Note: Significant differences within treatment cohorts among time points are indicated with different numbers of asterisks $(P<0.05)$. 
Table 3 Mean ( \pm standard deviation) graft and tibial tunnel dimensions from three-dimensional reconstructions of two-dimensional computed tomographic images obtained 4 and 8 weeks after tibial graft fixation with GraftGrab ${ }^{T M}$ or Bio-Post ${ }^{\text {TM }}$ implants

\begin{tabular}{|c|c|c|c|c|}
\hline & \multicolumn{2}{|c|}{ Week 4 after implantation } & \multicolumn{2}{|c|}{ Week 8 after implantation } \\
\hline & $\begin{array}{l}\text { GraftGrab } \\
n=7\end{array}$ & $\begin{array}{l}\text { Bio-Post } \\
n=7\end{array}$ & $\begin{array}{l}\text { GraftGrab } \\
n=7\end{array}$ & $\begin{array}{l}\text { Bio-Post } \\
n=7\end{array}$ \\
\hline Graft volume $\left(\mathrm{mm}^{3}\right)$ & $1727 \pm 360.1$ & $|887 \pm 37| .4$ & $1832 \pm 375.0$ & $1943 \pm 365.4$ \\
\hline Graft surface area $\left(\mathrm{mm}^{2}\right)$ & $1292 \pm 134.1$ & $1408 \pm 22 \mid .2$ & $1387 \pm 239.6$ & $1352 \pm 215.6$ \\
\hline Intra-articular graft volume $\left(\mathrm{mm}^{3}\right)$ & $943.8 \pm 302.6$ & $1057 \pm 246.6$ & $1040 \pm 279.5$ & $1148 \pm 148.7$ \\
\hline \multicolumn{5}{|l|}{ Intra-articular graft } \\
\hline surface area $\left(\mathrm{mm}^{2}\right)$ & $724.5 \pm 157.4$ & $790.2 \pm 124.7$ & $781.5 \pm 176.2$ & $777.8 \pm 81.9$ \\
\hline Intra-articular graft length (mm) & $21.7 \pm 3.1$ & $22.6 \pm 2.1$ & $22.4 \pm 3.1$ & $23.2 \pm 1.7$ \\
\hline Tibial tunnel volume $\left(\mathrm{mm}^{3}\right)$ & $591.1 \pm 113.2$ & $562.7 \pm 162$ & $563.2 \pm 154.1$ & $552.2 \pm 193$ \\
\hline \multicolumn{5}{|l|}{ Cortical tibial tunnel } \\
\hline exit circumference (mm) & $22.5 \pm 2.9$ & $21.6 \pm 2.6$ & $22.4 \pm 3.7$ & $19.8 \pm 6.2$ \\
\hline
\end{tabular}

We hypothesized that in vitro graft slippage would be lower and postoperative joint stability higher with the GG compared with the BP. The objective of this study was to compare the in vitro mechanical properties as well as in vivo joint laxity, graft and bone tunnel dimensions, postoperative limb use, and graft microstructure of the implants.

The canine stifle is not identical to the human knee anatomically or with respect to physiologic stresses and strains. Despite these limitations, the canine model of graft reconstruction is established to assess graft reconstruction and postimplantation outcomes for preclinical testing of devices and procedures for the human knee..$^{15,23,25-27}$ The graft defect that occurred in the GG cohort did not interfere with graft function because outcomes from the animal were not significantly different from others in either cohort. It is unlikely that the graft would have progressed to complete failure, but this could not be confirmed within the study duration. The mechanical testing values in this study are lower than would be expected for human tissues, primarily due to differences in graft diameter, ie, $4.5 \mathrm{~mm}$ for canines versus $10 \mathrm{~mm}$ for humans. This size differential was necessary to test the implant in the canine model. The device tunnel will be enlarged for human use without changing the overall profile and the mechanical characteristics of the implant will be evaluated prior to clinical testing.

Although the differences did not reach significance, the GG constructs had greater resistance to slippage immediately after fixation. They also tended to have higher failure and yield loads and stiffness immediately after fixation and eight weeks after implantation, inferring stronger, stiffer fixation. Bone tunnel-graft mechanical strength is reported to exceed intra-articular graft strength as early as 3 weeks following implantation. ${ }^{6}$ Mechanical values 8 weeks after implantation reflect graft properties, given that all failures occurred in graft tissue. Higher GG construct values could be due to better ligamentization owing to more stable anchorage. . $^{35,36}$

Significantly increased posterior tibial translation in the BP treatment group compared with preoperative values is consistent with increased joint laxity due to cyclical loading. Loss of cranial cruciate ligament function in the dog results in increased translational joint laxity that is, in part, due to increased posterior translation. ${ }^{26}$ The increased posterior laxity in the BP cohort 8

Table 4 Peak vertical force $(\mathbf{A})$ and vertical impulse (B) in limbs containing GraftGrab, Bio-Post, or no (control) implants preoperatively, and at 4 and 8 weeks after cranial cruciate ligament reconstruction (mean \pm standard deviation)

\begin{tabular}{|c|c|c|c|c|c|c|}
\hline & \multicolumn{3}{|c|}{ Peak vertical force (N/kg) } & \multicolumn{3}{|c|}{ Impulse ( $\mathbf{N} *$ sec/kg) } \\
\hline & $\begin{array}{l}\text { Before } \\
\text { surgery }\end{array}$ & Week 4 & Week 8 & $\begin{array}{l}\text { Before } \\
\text { surgery }\end{array}$ & Week 4 & Week 8 \\
\hline $\begin{array}{l}\text { GraftGrab } \\
n=7\end{array}$ & $6.9 \pm 0.7^{*}$ & $2.7 \pm 0.9 * *, a$ & $4.0 \pm 1.0^{* * *, a}$ & $1.0 \pm 0.1^{*}$ & $0.4 \pm 0.1 * *, a$ & $0.6 \pm 0.1 * * *, a$ \\
\hline $\begin{array}{l}\text { Bio-Post } \\
n=7\end{array}$ & $7.5 \pm 1.0 *$ & $3.3 \pm 1.3^{* *, \mathrm{a}}$ & $4.2 \pm 1.0^{* * *, a}$ & $1.0 \pm 0.1 *$ & $0.5 \pm 0.2^{* *, a}$ & $0.6 \pm 0.2^{* *, a}$ \\
\hline $\begin{array}{l}\text { Unoperated } \\
\mathrm{n}=14\end{array}$ & $7.0 \pm 0.9$ & $7.3 \pm 1.0^{b}$ & $7.5 \pm 0.9^{b}$ & $1.0 \pm 0.1 *$ & $1.2 \pm 0.2^{* *, b}$ & $1.2 \pm 0.1 * *, b$ \\
\hline
\end{tabular}

Notes: Significant differences among treatment cohorts at the different time points are indicated with different letters. Significant differences within treatment cohorts across time points are indicated with different numbers of asterisks $(P<0.05)$. 

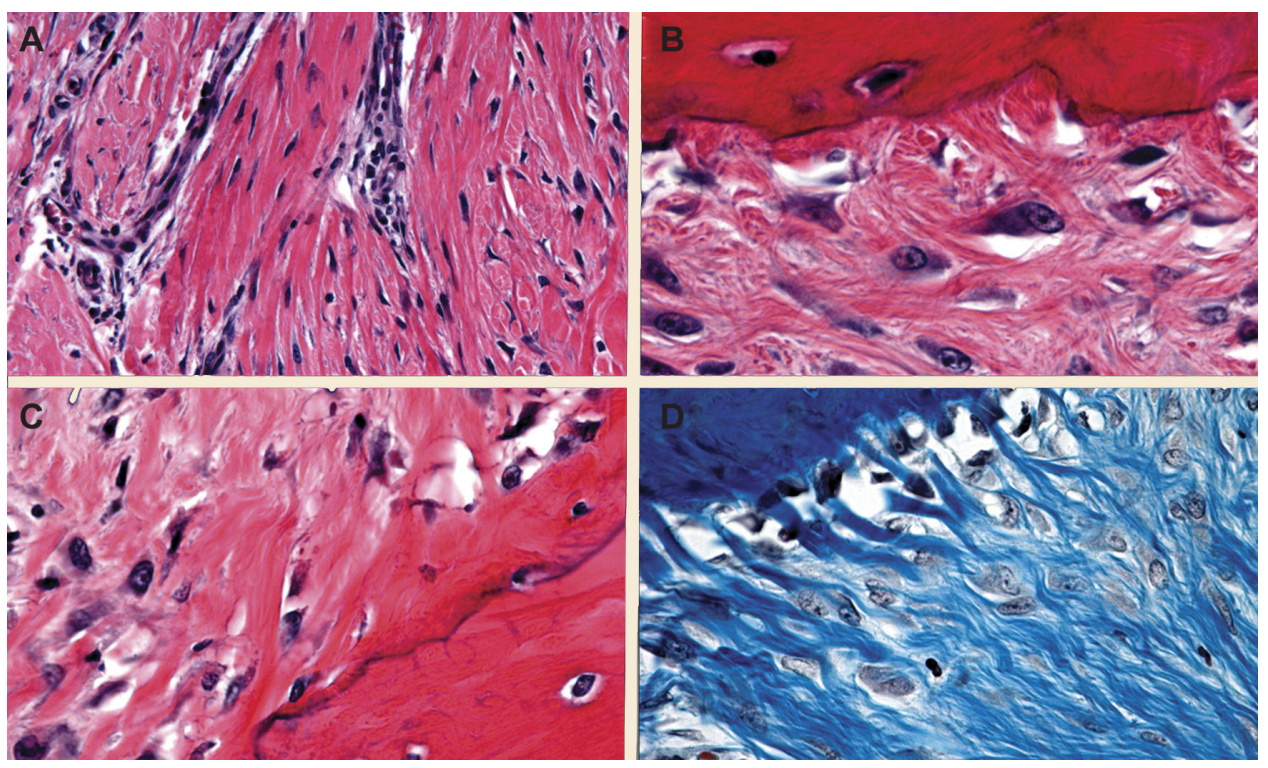

Figure 5 Photomicrographs of graft body (A) and attachment (B-D) demonstrating fibrous (B), direct (C), and indirect (D) graft insertions. Notes: Magnification A: 20x; B-D: 60x; A-C: hematoxylin and eosin staining; D: Masson's Trichrome.

weeks after implantation suggests that joint stabilization conferred by the grafts was reduced compared with the function of the intact ACL indicated by the presurgical values. There is a wide range of anterior-posterior displacements in normal and reconstructed human joints. ${ }^{10,37}$ To reduce variability between individuals in this study, values were normalized to tibial width as previously reported. ${ }^{26}$ Tibial translation is the most sensitive indication of ACL integrity and graft reconstruction function in humans, ${ }^{10,37}$ and has been shown to be equally sensitive in dogs for assessment of cranial cruciate ligament integrity. ${ }^{26}$ Therefore, it is not surprising, that changes in the BP cohort consistent with increasing joint laxity were detectable using this measure. The lack of differences in computed tomographic reconstructions may be explained by the fact that it is not possible to assess dynamic graft behavior under the static conditions during which the images were generated. Scans were performed with stifles in full extension and therefore do not reflect graft dimensions throughout the range of motion of the joint. Intra-articular graft surface area increased in the GG cohort, but decreased in the BP cohort between 4 and 8 weeks, potentially highlighting a tendency toward graft elongation.

Limb usage did not recover to the same degree in the BP as in the GG group based on vertical impulse values. The vertical impulse reflects the amount of force applied to the limb over time and the peak vertical force reflects the highest load experienced by the limb. The lack of increase in vertical impulse with an increase in peak vertical force between 4 and 8 weeks after surgery is consistent with limping. ${ }^{23,30,38}$ This finding supports slower return to normal use in limbs with the BP.
Microscopically, grafts were well integrated based on their attachments to bone. During graft integration, the number of fibrous, direct, and indirect insertions varies along the length of the intra tunnel graft. Direct insertions tend to be more prominent at the area with the greatest tensile stress while indirect insertions are highest at the more stable bonegraft interface. ${ }^{3}$ This is reportedly due to the fact that direct insertions absorb tensile stresses effectively through their four-layer interface with bone. ${ }^{39,40}$

Graft fixation, function, and integration ultimately determine the outcome of ACL reconstruction. ${ }^{17,19,20,25,41-44}$ The GG combines the advantages of extracortical fixation with simple implant application and graft affixation to reduce the potential for tension loss. Assessments in this study provide a comprehensive perspective of the GG, although in vitro fatigue testing and different in vivo study durations may highlight differences between implants. The results of this study support the GG as an alternative for extracortical tibial HG fixation that has procedural advantages over current implants, reduces graft failure from slippage, and results in consistent postoperative recovery in a canine model.

\section{Disclosure}

MJL and WTM are coinventors of the GraftGrab. Funding for this study was received from Tesa Medical Inc which has license to the patent rights for the GraftGrab. The patent rights are assigned to the Board of Supervisors of Louisiana State University and Agricultural and Mechanical College. The other authors have no conflicts of interest in this work. 


\section{References}

1. An YH, Woolf SK, Friedman RJ. Pre-clinical in vivo evaluation of orthopaedic bioabsorbable devices. Biomaterials. 2000;21(24): 2635-2652.

2. Buchner M, Schmeer T, Schmitt H. Anterior cruciate ligament reconstruction with quadrupled semitendinosus tendon - minimum 6 year clinical and radiological follow-up. Knee. 2007;14(4):321-327.

3. Chizari M, Snow M, Wang B. Post-operative analysis of ACL tibial fixation. Knee Surg Sports Traumatol Arthrosc. 2009;17(7):730-736.

4. Drogset JO, Strand T, Uppheim G, Odegard B, Boe A, Grontvedt T. Autologous patellar tendon and quadrupled hamstring grafts in anterior cruciate ligament reconstruction: a prospective randomized multicenter review of different fixation methods. Knee Surg Sports Traumatol Arthrosc. 2010;18(8):1085-1093.

5. Ekdahl M, Wang JH, Ronga M, Fu FH. Graft healing in anterior cruciate ligament reconstruction. Knee Surg Sports Traumatol Arthrosc. 2008; 16(10):935-947.

6. Grana WA, Egle DM, Mahnken R, Goodhart CW. An analysis of autograft fixation after anterior cruciate ligament reconstruction in a rabbit model. Am J Sports Med. 1994;22(3):344-351.

7. Tyler TF, McHugh MP, Gleim GW, Nicholas SJ. Association of KT-1000 measurements with clinical tests of knee stability 1 year following anterior cruciate ligament reconstruction. J Orthop Sports Phys Ther. 1999;29(9):540-545.

8. Woo SL, Wu C, Dede O, Vercillo F, Noorani S. Biomechanics and anterior cruciate ligament reconstruction. J Orthop Surg Res. 2006;1:2.

9. Grover DM, Howell SM, Hull ML. Early tension loss in an anterior cruciate ligament graft. A cadaver study of four tibial fixation devices J Bone Joint Surg Am. 2005;87(2):381-390.

10. Daniel DM, Stone ML, Sachs R, Malcom L. Instrumented measurement of anterior knee laxity in patients with acute anterior cruciate ligament disruption. Am J Sports Med. 1985;13(6):401-407.

11. Roos PJ, Hull ML, Howell SM. Lengthening of double-looped tendon graft constructs in three regions after cyclic loading: a study using Roentgen stereophotogrammetric analysis. J Orthop Res. 2004; 22(4):839-846.

12. Hapa O, Barber FA. ACL fixation devices. Sports Med Arthrosc. 2009; 17(4):217-223.

13. Grover D, Thompson D, Hull ML, Howell SM. Empirical relationship between lengthening an anterior cruciate ligament graft and increases in knee anterior laxity: a human cadaveric study. J Biomech Eng. 2006; 128(6):969-972.

14. Thompson DM, Hull ML, Howell SM. Does a tensioning device pinned to the tibia improve knee anterior-posterior load-displacement compared to manual tensioning of the graft following anterior cruciate ligament reconstruction? A cadaveric study of two tibial fixation devices. J Orthop Res. 2006;24(9):1832-1841.

15. Tohyama H, Beynnon BD, Johnson RJ, Renstrom PA, Arms SW. The effect of anterior cruciate ligament graft elongation at the time of implantation on the biomechanical behavior of the graft and knee. $\mathrm{Am}$ J Sports Med. 1996;24(5):608-614.

16. Fabbriciani C, Mulas PD, Ziranu F, Deriu L, Zarelli D, Milano G. Mechanical analysis of fixation methods for anterior cruciate ligament reconstruction with hamstring tendon graft. An experimental study in sheep knees. Knee. 2005;12(2):135-138.

17. Kousa P, Jarvinen TL, Vihavainen M, Kannus P, Jarvinen M. The fixation strength of six hamstring tendon graft fixation devices in anterior cruciate ligament reconstruction. Part II: tibial site. Am J Sports Med. 2003;31(2):182-188

18. Brand J Jr, Weiler A, Caborn DN, Brown CH Jr, Johnson DL. Graft fixation in cruciate ligament reconstruction. Am J Sports Med. 2000; 28(5):761-774.

19. Giurea M, Zorilla P, Amis AA, Aichroth P. Comparative pull-out and cyclic-loading strength tests of anchorage of hamstring tendon grafts in anterior cruciate ligament reconstruction. Am J Sports Med. 1999; 27(5):621-625.
20. Magen HE, Howell SM, Hull ML. Structural properties of six tibial fixation methods for anterior cruciate ligament soft tissue grafts. $\mathrm{Am} \mathrm{J}$ Sports Med. 1999;27(1):35-43.

21. Liu-Barba D, Howell SM, Hull ML. High-stiffness distal fixation restores anterior laxity and stiffness as well as joint line fixation with an interference screw. Am J Sports Med. 2007;35(12): 2073-2082.

22. Shelbourne KD, Gray T. Anterior cruciate ligament reconstruction with autogenous patellar tendon graft followed by accelerated rehabilitation. A two- to nine-year followup. Am J Sports Med. 1997; 25(6):786-795.

23. Lopez MJ, Markel MD, Kalscheur V, Lu Y, Manley PA. Hamstring graft technique for stabilization of canine cranial cruciate ligament deficient stifles. Vet Surg. 2003;32(4):390-401.

24. Snow LA, White R, Gustafson S, et al. Ex vivo comparison of three surgical techniques to stabilize canine cranial cruciate ligament deficient stifles. Vet Surg. 2010;39(2):195-207.

25. Lopez MJ, Spencer N, Casey JP, Monroe WT. Biomechanical characteristics of an implant used to secure semitendinosus-gracilis tendon grafts in a canine model of extra-articular anterior cruciate ligament reconstruction. Vet Surg. 2007;36(6):599-604.

26. Lopez MJ, Hagquist W, Jeffrey SL, Gilbertson S, Markel MD. Instrumented measurement of in vivo anterior-posterior translation in the canine knee to assess anterior cruciate integrity. J Orthop Res. 2004;22(5):949-954.

27. Lopez MJ, Markel MD. Anterior cruciate ligament rupture after thermal treatment in a canine model. Am J Sports Med. 2003;31(2): 164-167.

28. Ishii D, Ying TH, Mahara A, et al. In vivo tissue response and degradation behavior of PLLA and stereocomplexed PLA nanofibers. Biomacromolecules. 2009;10(2):237-242.

29. Purnell ML, Larson AI, Clancy W. Anterior cruciate ligament insertions on the tibia and femur and their relationships to critical bony landmarks using high-resolution volume-rendering computed tomography. Am J Sports Med. 2008;36(11):2083-2090.

30. Lopez MJ, Quinn MM, Markel MD. Evaluation of gait kinetics in puppies with coxofemoral joint laxity. Am J Vet Res. 2006; 67(2):236-241.

31. D'Amico LL, Xie L, Abell LK, Brown KT, Lopez MJ. Relationships of hip joint volume ratios with degrees of joint laxity and degenerative disease from youth to maturity in a canine population predisposed to hip joint osteoarthritis. Am J Vet Res. 2011;72(3):376-383.

32. Claes S, Verdonk P, Forsyth R, Bellemans J. The "ligamentization" process in anterior cruciate ligament reconstruction: what happens to the human graft? A systematic review of the literature. Am J Sports Med. 2011;39(11):2476-2483.

33. Khan R, Konyves A, Rama KR, Thomas R, Amis AA. RSA can measure ACL graft stretching and migration: development of a new method. Clin Orthop Relat Res. 2006;448:139-145.

34. Rhee PC, Dahm DL, Stuart MJ, Thoreson A, An KN, Levy BA. Delta screw versus RetroScrew tibial fixation for ACL reconstruction. Knee Surg Sports Traumatol Arthrosc. 2011;19 Suppl 1:94-100.

35. Amiel D, Kleiner JB, Roux RD, Harwood FL, Akeson WH. The phenomenon of "ligamentization": anterior cruciate ligament reconstruction with autogenous patellar tendon. J Orthop Res. 1986; $4(2): 162-172$.

36. Deehan DJ, Cawston TE. The biology of integration of the anterior cruciate ligament. J Bone Joint Surg Br. 2005;87(7):889-895.

37. Smith CK, Howell SM, Hull ML. Anterior laxity, slippage, and recovery of function in the first year after tibialis allograft anterior cruciate ligament reconstruction. Am J Sports Med. 2011;39(1):78-88.

38. Budsberg SC, Verstraete MC, Soutas-Little RW. Force plate analysis of the walking gait in healthy dogs. Am JVet Res. 1987;48(6): 915-918.

39. Harvey A, Thomas NP, Amis AA. Fixation of the graft in reconstruction of the anterior cruciate ligament. J Bone Joint Surg Br. 2005;87(5): 593-603. 
40. Weiler A, Hoffmann RF, Bail HJ, Rehm O, Sudkamp NP. Tendon healing in a bone tunnel. Part II: Histologic analysis after biodegradable interference fit fixation in a model of anterior cruciate ligament reconstruction in sheep. Arthroscopy. 2002;18(2):124-135.

41. Kousa P, Jarvinen TL, Vihavainen M, Kannus P, Jarvinen M. The fixation strength of six hamstring tendon graft fixation devices in anterior cruciate ligament reconstruction. Part I: femoral site. Am J Sports Med. 2003;31(2):174-181.

42. Monaco E, Labianca L, Speranza A, et al. Biomechanical evaluation of different anterior cruciate ligament fixation techniques for hamstring graft. J Orthop Sci. 2010;15(1):125-131.
43. Rodeo SA, Arnoczky SP, Torzilli PA, Hidaka C, Warren RF. Tendonhealing in a bone tunnel. A biomechanical and histological study in the dog. J Bone Joint Surg Am. 1993;75(12):1795-1803.

44. Weiler A, Hoffmann RF, Stahelin AC, Bail HJ, Siepe CJ, Sudkamp NP. Hamstring tendon fixation using interference screws: a biomechanical study in calf tibial bone. Arthroscopy. 1998;14(1):29-37.

\section{Publish your work in this journal}

Medical Devices: Evidence and Research is an international, peerreviewed, open access journal that focuses on the evidence, technology, research, and expert opinion supporting the use and application of medical devices in the diagnosis, treatment and management of clinical conditions and physiological processes. The identification of novel devices and optimal use of existing devices which will lead to improved clinical outcomes and more effective patient management and safety is a key feature. The manuscript management system is completely online and includes a quick and fair peer-review system. Visit http://www. dovepress.com/testimonials.php to read real quotes from authors.

Submit your manuscript here: http://www.dovepress.com/medical-devices-evidence-and-research-journal 